\title{
LA PEREGRINACIÓN AL SANTUARIO DE CHAPI: UNA PROPUESTA DE RUTA RELIGIOSA TURÍSTICA EN AREQUIPA
}

\author{
THE PILGRIMAGE TO THE CHAPI SANCTUARY: \\ A PROPOSAL FOR A RELIGIOUS TOURISTIC ROUTE IN AREQUIPA
}

\author{
Alejandro Málaga Núñez-Zeballos \\ Universidad San Agustín de Arequipa, Perú
}

\section{RESUMEN}

En los últimos años, a nivel mundial el turismo religioso ha cobrado importancia debido al flujo de visitantes que generan significativos dividendos a la población del lugar. En esa línea de investigación, el presente trabajo enfoca y analiza a la peregrinación más numerosa e importante del Sur andino, a una imagen de la virgen María, a la llamada «Mamita de Chapi», en el santuario del mismo nombre a $76 \mathrm{~km}$ de la ciudad de Arequipa, Perú. El presente artículo estudia el origen, trayectoria y estado actual del santuario y resalta los elementos para crear una ruta turística religiosa que sería la primera de la región.

Palabras clave: Turismo religioso, peregrinación, ruta, Virgen de Chapi.

\begin{abstract}
In recent years, religious tourism has been on the rise around the world due to the significant economic benefits for the local population that result from such activity. This article describes and analyzes the largest and most important pilgrimage of the southern Andes, which is directed at an image of the Virgin Mary, called the Mamita de Chapi, located in a sanctuary 76 kilometers outside of the city of Arequipa, Peru. This work studies the origin, trajectory, and current status of the sanctuary and highlights important elements for creating the first religious touristic route in the region.
\end{abstract}

Keywords: Religious tourism, pilgrimage, route, Virgin of Chapi 


\section{Introducción}

El Perú, cuenta con innumerables fiestas religiosas, ya que cada ciudad tiene como patrona o patrón a una virgen, santo, espíritu santo, etc. que a la fecha esperan ser inventariadas y tal vez convertidas en una propuesta de ruta turística religiosa. La mayoría de las festividades como la Candelaria de Puno, la Semana Santa de Cusco, la Virgen del Carmen de Paucartambo, etc., son singulares por sus características multiculturales mostrando un sincretismo religioso único; sin embargo, ninguna de ellas es una peregrinación a una virgen, por ello nuestro interés en estudiar y proponer una alternativa turística diferente para Arequipa.

\section{Objetivo}

El presente artículo tiene como objetivo mostrar la viabilidad de la propuesta de una ruta religiosa, en dos modalidades: por la vía terrestre en auto cualquier día del año, y caminando a través de senderos que solo en el mes de mayo son recorridos por los devotos que van al santuario.

\section{El territorio y sus elementos culturales}

En el siglo XV, se produjo un desequilibrio ecológico en el Altiplano peruano-boliviano, a causa de la excesiva lluvia se incrementaron las aguas del lago Titicaca y paulatinamente se fue desbordando, afectando los campos de cultivos de los habitantes de los alrededores definidos como los «reinos lacustres del Titicaca».

Las investigaciones arqueológicas e históricas, han identificado a varias sociedades andinas que migraron a otros territorios para establecerse y posiblemente empezar de nuevo, la más conocida es de los quechuas, quienes se movilizaron hasta llegar al Cusco y desde allí se expandieron edificando un imperio. Caso similar son los puquina, un grupo de ellos abandonaron al lago sagrado y viajaron para establecerse en la actual frontera de los departamentos de Arequipa y Moquegua. Un siglo después, cuando se produjo la colonización hispana, las autoridades reales crearon en el territorio nuevas jurisdicciones, el área en mención, fue definida como el corregimiento de Arequipa, en su interior en la zona estudiada figuran en un mapa de fines de siglo XVIII, cinco pueblos: Ubinas, Carumas, Puquina, Cochuna y Pocsi, el pueblo más importante.

Los españoles que recorrieron y habitaron la zona, se dieron cuenta que los puquina estaban muy bien organizados, habían edificado una infraestructura muy eficaz integrada por numerosos andenes que bordean los cerros, una red de canales por donde fluía el agua desde los deshielos de los nevados cercanos como el Pichupichu, una ciudadela, su cementerio y lo más importante, un lugar ceremonial en el que rindieron culto a la deidad de toda la zona, el dios Pichinique, que fue descrito por un religioso agustino como la cara de una persona muy fea con cuerpo de serpiente que se aparecía y salía del agua de los ríos y estanques que existieron (Calancha, 1638).

Los puquinas se comunicaron en su propia lengua, algunos fueron los traductores con los pueblos vecinos que hablaban aymará, quechua y coli; por ello, la evangelización se tornó como un caso singular y en una tarea muy difícil. Desde la ciudad de Moquegua los religiosos jesuitas iniciaron la evangelización y eligieron como advocación a la Virgen Candelaria que ya había tenido éxito en ser aceptada por la población andina en 
otros lugares como Cayma y Characato en Arequipa, la ciudad de Puno, y Copacabana, en la segunda mitad del siglo XVI.

El origen de la veneración a esta Virgen Candelaria, tiene varias versiones orales muchas de las cuales son fantasías del peregrino a lo largo de siglos, por ejemplo, se cree que en la época colonial unos arrieros viajaban por la zona hacia el Altiplano con dirección a Potosí, casualmente olvidaron una caja que contenía dicha imagen e interpretaron que la virgen quería quedarse en ese lugar.

Otra versión de la época colonial cuenta que un enfermo incurable fue al lugar donde hay un pequeño «ojo de agua», bebió unos sorbos y humedeció todo su cuerpo, se sintió curado y volvió a su casa. Cuando dormía soñó con una mujer que le dijo ser la autora de su curación y que ella estaba esperando a que él la encuentre. Al día siguiente, el hombre recorrió los alrededores y encontró envuelta en unos trapos la imagen, maravillado con el suceso difundió la noticia (Morote Best, 1988).

En 1600, erupcionó el volcán Huaynaputina y las consecuencias fueron devastadoras, los constantes movimientos telúricos derrumbaron todas las construcciones, los gases piroplásticos aniquilaron a todo ser viviente y la lluvia de cenizas y material expulsado al aire generaron la catástrofe más destructiva de la historia de Sudamérica.

La imagen de la virgen fue llevada del lugar llamado Sahuaca a otro denominado Chaypi, que posteriormente sería identificado como Chapi y allí se quedó hasta ahora. La población de Chapi vivía en los pueblos tradicionales de Polobaya y Pocsi, en 1793, el padre Francisco Pantaleón de Ustáriz párroco de Pocsi, le informó al obispo de la ciudad Pedro José Chávez de la Rosa, que unos indios de la quebrada de Chapi se reconocían como protectores de la imagen y alegaban que no debería ser llevada a otro, el prelado ordenó que permanezca.

Desde 1884, los lugareños de la zona empezaron a trabajar en la ampliación y embellecimiento de la primitiva capilla y diez años más tarde, el señor Manuel Arrieta encabezó un grupo de devotos que solventaron las obras y se concluyó el templo; lamentablemente, el 3 de mayo de 1922, a causa de las velas, se incendió quedando solamente la imagen. Poco tiempo después, la colectividad arequipeña con sus donativos propició la construcción de otra iglesia que fue finalizada a mediados del siglo pasado y demolida por estar muy afectada por el terremoto del año 2001.

El 20 de octubre de 1952, el arzobispo monseñor José Leonardo Rodríguez Ballón, elevó el Santuario de Chapi a la categoría de capellanía. En 1985 el Estado donó $267.813 \mathrm{~m}^{2}$ por Ley 24023 del 11 de diciembre, adjudicando la venta al Arzobispado de Arequipa como propiedad del santuario. El 21 de abril de 1986, el templo fue elevado a Santuario Arquidiocesano (Málaga, 2011).

\section{Prestigio y devoción religiosa}

El milagro que más recuerda la población arequipeña, es la voluntad de la Virgen de querer quedarse en el lugar para ser venerada. Existen versiones personales o colectivas como la que cuenta que catorce peones 
cortaban sillares para la construcción de la iglesia y la carencia de agua hacía más ardua su labor, una noche uno de los obreros acudió al santuario y con mucha fe le imploró a la virgen solucione la necesidad; al día siguiente, a unos veinte metros de la cantera descubrieron un poco de humedad y poco a poco brotó un ojo de agua. Uno de los obreros que padecía de la vista, se lavó los ojos con el agua y se alivió.

Son innumerables los milagros atribuidos a esta Candelaria, no solo por los habitantes de Pocsi y alrededores, sino de Yarabamba, Quequeña, Sogay, Sabandía, Characato, Paucarpata y paulatinamente la población de la ciudad de Arequipa, siendo la salud el principal tema solicitado a la Virgen de Chapi.

La imagen siempre fue llevada en procesión alrededor de su templo, porque existía y aún existe el temor de la población si deja el lugar, podría ocurrir algún desastre. En 1983, el arzobispo de Arequipa monseñor Fernando Vargas Ruiz de Somocurcio S. J. decidió que la Virgen de Chapi visite la ciudad y finalice la terrible sequía que asolaba la campiña por varios años, a pesar de la negativa de los pobladores de los pueblos aledaños, la imagen fue llevada a la ciudad y permaneció dos meses.

El 2 de febrero de 1985, su santidad Juan Pablo II estando en Arequipa beatificó a la religiosa dominica sor Ana de los Ángeles Monteagudo y coronó a la Virgen de Chapi. Ese mismo año, el 5 de diciembre el gobierno peruano le confirió la «Orden del Sol del Perú», por sus méritos y servicios a la colectividad, el 23 de setiembre de 1990 le otorgaron las «Alas de la Fuerza Aérea del Perú»; presidentes, alcaldes, instituciones educativas, instituciones privadas, asociaciones, etc., han distinguido a la Virgen de Chapi con innumerables condecoraciones y honores.

\section{Peregrinaciones y festividades}

El primer obispo que fue a ver la imagen en peregrinación, fue monseñor Manuel Segundo Ballón en 1901, fortaleciendo dicha práctica entre los devotos. En la actualidad, cada vez son más los integrantes de las peregrinaciones, la más numerosa es en mayo, se parte de alguna parroquia de la ciudad o casa de amigos, recorriendo los distritos de Paucarpata, Sabandía, Characato hasta llegar a Yarabamba, Sogay, la Primera Apacheta señalada con tres cruces, Alto de Hornillos, la Pampa Tumbambay, la Segunda Apacheta, la Pampa del Tolar, Siete Toldos, la Tercera Apacheta o Alto de la Escalerilla y finalmente el santuario. Cabe resaltar que todo el recorrido es por un sendero de tierra y piedras, a través de las quebradas, subiendo y bajando cerros inhóspitos.

La festividad oficial es el 2 de febrero por ser Candelaria, sin embargo, ese día casi nadie va al santuario porque prefieren ir el 1 de mayo, fecha establecida desde 1876 por el Padre Emeterio Retamoso. Es el día en que más devotos y peregrinos acuden al santuario. También los fieles acuden el 8 de setiembre desde 1907, por ser la fecha de la Natividad de la Virgen y el 8 de diciembre desde 1940 a pedido de los mineros informales de la zona. A lo largo del año pasado, acudieron más de 300,000 devotos, la mayoría fue en mayo.

La imagen de la Virgen de Chapi es la advocación que ha cobrado más fuerza en la región, los devotos desde hace tres décadas empezaron a referirse a ella, como la «Mamita de Chapi», en sentido afectuoso y como imagen materna que consuela a sus hijos. 
Han surgido innumerables capillas con imágenes copias de la de Chapi. Así, tenemos la de Chapi Chico, en el distrito de Miraflores que surgió a iniciativa de un grupo de pobladores hacia 1931. La Virgen de Chapi de Charcani, cuya leyenda indica que fue encontrada por un indio que bajó al río a llevar agua y se encontró con una mujer sentada sobre una piedra, cuando terminó de llenar su cántaro se dio con la sorpresa que aquella señora no se hallaba sino estampada en una piedra, avisó inmediatamente del prodigio al párroco de La Tomilla y se difundió la feliz noticia.

En la Tercera Orden, hay también una imagen que dicen que es la original de Chapi y que fue cambiada, hay otra versión que dice que un artesano la dejó una mañana en la entrada del templo envuelta en sábanas y así fue encontrada. Casi todas las iglesias de la región tienen un altar a la «Mamita de Chapi», muchas personas suelen llevar estampas o pequeñas imagen de ella en sus vehículos: autos, camionetas, camiones, omnibuses, etc.; edificios, negocios, viviendas, parques, etc., buscando protección en ella.

\section{Propuesta de una ruta turística religiosa}

El turismo religioso ha sido definido o conceptualizado a partir de la fe, la cual es el elemento motivador que genera las movilizaciones de millones de personas de distintas religiones, a distintos lugares como el Vaticano, La Meca, el Tibet, miles de santuarios y lugares sagrados alrededor del mundo.

Un conocido diccionario sobre el tema, señala: «actividad turística que consiste en realizar viajes (peregrinaciones) o estancias en lugares religiosos (retiros espirituales, actividades culturales y liturgias religiosas, etc.), que para los practicantes de una religión determinada supone un fervor religioso por ser lugares sagrados de veneración, o preceptuales según su credo» (Montaner, Antiach y Arcarons, 1998).

La práctica del turismo en lugares o espacios religiosos, también ha sido definida como turismo cultural, actividad en la cual el viajero visita el lugar -sin ser creyente- y a veces se integra a la festividad religiosa, la cual es percibida por el visitante desde su perspectiva de carácter patrimonial.

El acto de peregrinar de un lugar a otro, es una práctica netamente religiosa, ya que la devoción a ese lugar o imagen, es la que dinamiza esta movilización de creyentes en fechas establecidas por la organización. Algunos especialistas consideran que es una forma de turismo, ya que visitantes que se enteran de un lugar sagrado y posterior peregrinación, se integran para viajar, conocer el lugar y participar en la vivencia de la localidad.

En la articulación de las peregrinaciones religiosas, podemos reconocer los siguientes elementos:

a. La ruta o rutas que son recorridas en ciertas fechas por los devotos, para poder llegar al santuario, que también sirven para regresar a la ciudad. El camino que se va a recorrer en la mayoría de casos es conocido o familiar y a medida que el peregrino se va acercando al santuario, sus emociones van aflorando, ya que llega al espacio sagrado en el cual conseguirá satisfacción espiritual. 
b. El complejo arquitectónico del santuario y su entorno geográfico. El templo viejo y el nuevo en los que se realizan constantemente misas cada hora los días de fiesta, la explanada para las procesiones, bendiciones y verbenas, los techos que cobijan a los peregrinos que llegan a pie luego de caminar unas ocho horas, los establecimientos (restaurantes y kioskos) que expenden alimentos y bebidas que ofrecen todo tipo de potajes para recuperar las fuerzas y retornar. Los puestos de venta que ofrecen recuerdos como: estampas, cadenas, recuerdos, afiches y hasta agua bendita.

c. El impacto que ocasiona la movilización de miles de visitantes en la ciudad, a lo largo de la ruta o rutas, en el mismo santuario y de regreso.

Algunos autores como Vukonic (1997) no dudan en relacionar a la peregrinación con el concepto de turismo religioso, basándose en el hecho de que el comportamiento de peregrinos y turistas es similar tanto durante el viaje como durante la estancia en el destino, diferenciándose tan solo en las motivaciones.

Para el caso arequipeño, la peregrinación se realiza desde la Plaza Mayor de la ciudad de Arequipa al santuario de Chapi, ubicado en el distrito de Polobaya, son $76 \mathrm{~km}$ aproximadamente que se encuentran en su mayoría muy bien asfaltados y señalizados.

El santuario está integrado por el antiguo templo que data de fines del siglo XIX, una nueva iglesia, las plataformas para las procesiones y un pequeño alberque para los peregrinos que es insuficiente, hay señal de celular en la parte superior de los cerros. En los alrededores del inconcluso complejo religioso, en las principales fechas se reabren los restaurantes que la mayor parte del año se encuentran cerrados, además, son armados innumerables kioskos que también expenden alimentos. Hay la carencia de servicios básicos como agua, desagüe, luz, posta médica, que son suplidos con tanques cisternas que llenan algunos depósitos para baños improvisados. No existen locales para hospedarse, la información que se brinda al visitante en folletos, muchas veces es contradictoria porque son datos errados tanto geográficos como históricos, generando confusión entre los devotos y visitantes.

A pesar de todo ello, los devotos y visitantes acuden por un día en su movilidad o bus, o en mayo realizan su peregrinaje a pie. Entonces, son dos las formas de llegar al santuario: en movilidad en las fiestas principales o cualquier día del año, y peregrinando principalmente en mayo; cabe resaltar, que casi toda la ruta a pie no es por la carretera, sino a través de un sendero de tierra que recorre las faldas y cimas de cerros, quebradas, pampas y suelos pedregosos, por lo general, los peregrinos parten en la tarde y luego de casi ocho horas llegan al amanecer al santuario a visitar a la Virgen de Chapi.

Si hay una coordinación efectiva entre el Arzobispado de Arequipa, Municipalidad de Polobaya, Policía Nacional del Perú y las asociaciones de guías de la ciudad se podría ofertar la ruta a Chapi a pie en el mes de mayo o febrero. Debe haber una sensibilización de buenas prácticas a los habitantes que ofrecen sus servicios en Chapi, así como debe difundirse la información real y verdadera sobre la historia de dicho santuario.

El visitante y peregrino solo permanecen unas horas acudiendo a la celebración de la misa, recuperándose tomando sus alimentos y luego retornar a la ciudad, cabe resaltar que todos los peregrinos no regresan caminando, 
sino con el transporte de buses, combis, autos. Cada uno adquiere un recuerdo del santuario como: detente, estampa, llavero, cuadro, afiche, y hasta agua bendita.

\section{Consideraciones finales}

Visitar el Santuario de la Virgen de Chapi puede convertirse en una atractiva ruta turística religiosa, ya que en la actualidad es la devoción que atrae a más devotos y fieles del sur del Perú; por ello, se debe crear un plan de operaciones mancomunado entre las instituciones gubernamentales y religiosas como el Gobierno Regional de Arequipa, Municipalidad Provincial de Arequipa, distritos por donde transita la peregrinación: Cercado, Miraflores, José Luís Bustamante y Rivero, Socabaya, Paucarpata, Sabandía, Yarabamba, Posci y Polobaya, y el Arzobispado de Arequipa; además, deben participar la Policía Nacional del Perú, Cruz Roja y Bomberos.

Las instituciones vinculadas al turismo como las agencias, deberían elaborar un diagnósticos del atractivo y posteriormente desarrollar un plan efectivo que primero implemente los servicios básicos de los que carece el santuario, culminación de la infraestructura para pernoctar, organizar a los comerciantes y expendedores de alimentos para que no generen un caos entre los visitantes, ofrecer la información real en base a un estudio histórico para que se incremente la identidad local y religiosa, promocionar la oferta de paquetes turísticos en las fechas festivas difundiéndose con anticipación por distintos medios de comunicación.

La propuesta y su difusión dependen de la concertación de las instituciones mencionadas, para que se oficialice y funcione de manera más adecuada ya que trae un buen porcentaje de dividendos a la población local y de paso refuerza la oferta de atractivos turísticos de la región Arequipa. 


\section{Referencias}

Calancha, A. (1638). Crónica moralizadora de la Orden de San Agustín del Perú, con sucesos ejemplares de esta Monarquía.

Barcelona: Imprenta de Pedro Lacavallería.

Málaga, A. (2011). La Virgen de Arequipa. Historia de la milagrosa Virgen de Chapi. Arequipa: Universidad Católica de Santa

María. Montaner, J., Antiach, J., \& Arcarons, R. (1998). Diccionario de turismo. Madrid: Síntesis.

Morote Best, E. (1988). Aldeas sumergidas: cultura popular y sociedad en los Andes. Cuzco: Centro de Estudios Regionales Andinos Bartolomé de las Casas.

Vukonic, B. (1996). Tourism and religion. New York: Editorial Pergamon.

\section{Bibliografía recomendada}

Donaire, J. A. (2012). Turismo cultural. Entre la experiencia y el ritual. Barcelona: Vitel-la.

Esteve, R. (2002). Turismo y religión. Aproximación a la historia del turismo religioso. Málaga: Universidad de

Málaga. Fernández Fuster, L. (1985). Teoría y técnica del turismo. Madrid: Editora Nacional.

Gobierno Regional de Arequipa (2007). La ruta del loncco. Arequipa.

Martorell, A. (2010). Itinerarios culturales y patrimonio mundial. Lima: Universidad de San Martín de Porres. Neyra,

M. et al. (1990). Historia general de Arequipa. Arequipa: Fundación Manuel J. Bustamante de la Fuente.

Puccio, H. (2016). El turismo y su relación con la religiosidad popular. Recuperado de http://observatoriogeograficoamericalatina.org.mx/ egal8/Geografiasocioeconomica/Geografiaturistica/27.pdf

Razaq, R. \& Morphet, N. (2007). Religious tourism and pilgrimage festivals and management. An international perspective. Cambridge: CABI.

Romo Guijarro, J. A. (2001). El uso turístico del espacio religioso: El Santuario de Loiola. Deusto: Instituto de Estudios de Ocio, Universidad de Deusto. 


\section{ANEXO 1}

Se han escrito muchas canciones y oraciones para aliviar el penoso y duro camino de los devotos, de $L a$ Canción del Peregrino tenemos estas estrofas que son las más repetidas durante el trayecto de la peregrinación.

A tus pies Señora

cansado llegué,

cercado de angustias

Y de penas mil.

¡Ay! dulce María

De mi corazón

Tú eres la esperanza

De mi salvación.

Sólo en tu mirada

Hallo dulce paz

Esa paz que el mundo

No me puede dar.

Otra canción del peregrino.

Primero de Mayo

dedicado a Ti.

¡Oh Virgen de Chapi!

de mi corazón.

AVE, AVE, AVE MARÍA

AVE, AVE, AVE MARÍA
Desde Paucarpata

pensando en María

y sin darme cuenta

llegué a Sabandía.

Ya en Characato se

pierde el verdor más

en Yarabamba se

enciende mi amor.

De las Pampas Nuevas

a Cuesta de Hornillos

quebradas y cerros

hasta Tumbambay.

Pampa del Tolar y

al Cruce llegué

hasta Siete Toldos

para descansar.

Oigo las campanas ¡cansansio adios! su mano me alcanza la Madre de Dios.

\section{ANEXO 2}

\section{Oración a la Santísima Virgen de Chapi}

Bendita Sea tu pureza

Y eterna los sea,

Pues todo un Dios se recrea

En tan graciosa belleza.

A Ti, Celestial Princesa,

Virgen Sagrada María,

Yo te Ofrezco en este Día

Alma, vida, y corazón;

Mírame con compasión;

No me dejes Madre mía,

Morir sin tu bendición. 


\section{ANEXO 3}

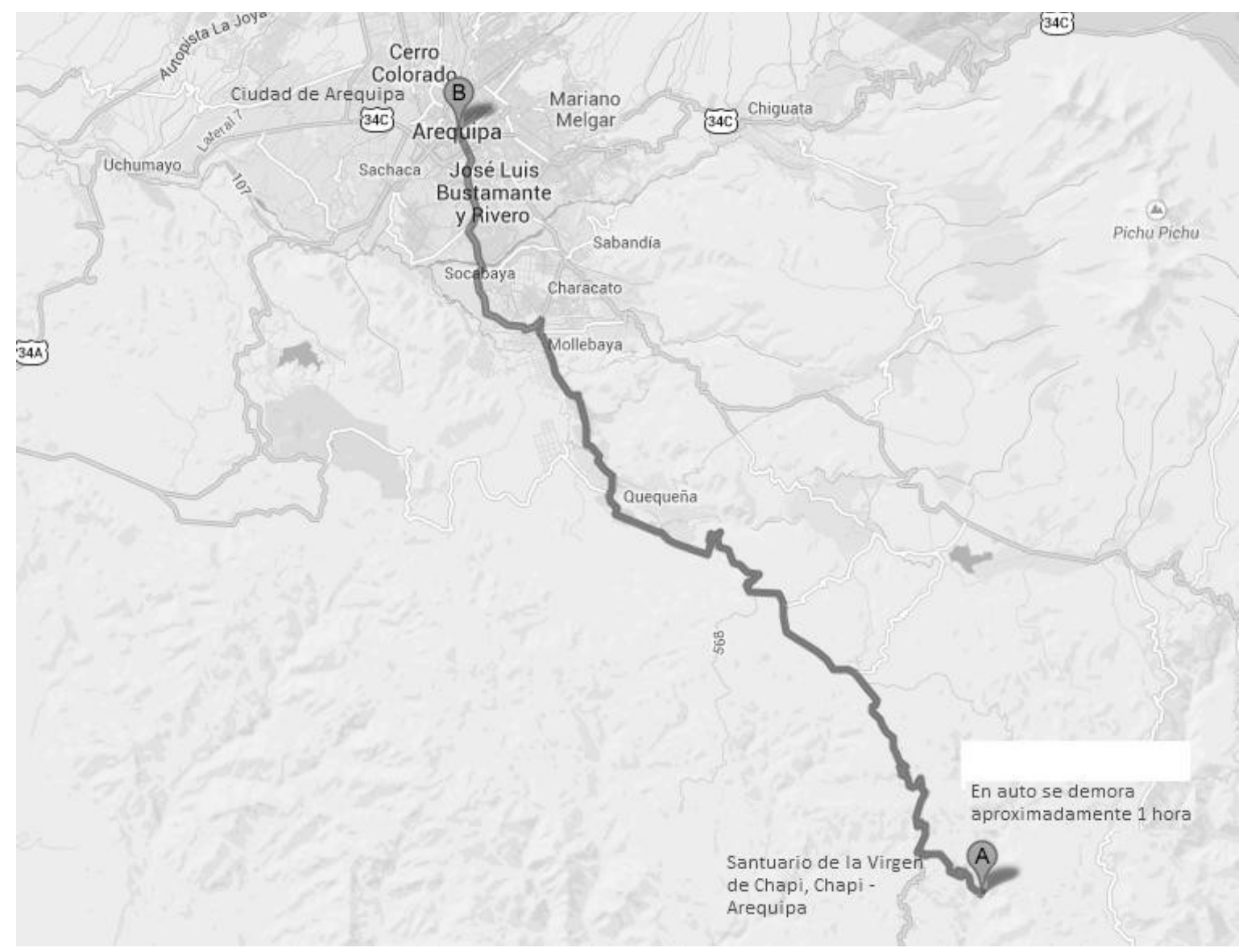

https://www.google.com.pe/search?q=ruta+a+pie+al+santuario+de+chapi\&rlz= 